\title{
Diffusion tensor imaging for assessment of microstructural changes associate with treatment outcome at one-year after radiofrequency Rhizotomy in trigeminal neuralgia
}

Shu-Tian Chen ${ }^{1}$, Jen-Tsung Yang ${ }^{2}$, Hsu-Huei Weng ${ }^{1}$, Hsueh-Lin Wang ${ }^{1}$, Mei-Yu Yeh ${ }^{3}$ and Yuan-Hsiung Tsai ${ }^{1 *}$

\begin{abstract}
Background: Trigeminal neuralgia (TN) is characterized by facial pain that may be sudden, intense, and recurrent. Neurosurgical interventions, such as radiofrequency rhizotomy, can relieve TN pain, but their mechanisms and effects are unknown. The aim of the present study was to investigate the microstructural tissue changes of the trigeminal nerve (TGN) in patients with TN after they underwent radiofrequency rhizotomy.

Methods: Thirty-seven patients with TN were recruited, and diffusion tensor imaging was obtained before and two weeks after radiofrequency rhizotomy. By manually selecting the cisternal segment of the TGN, we measured the volume of the TGN, fractional anisotropy (FA), apparent diffusion coefficient (ADC), axial diffusivity (AD), and radial diffusivity (RD). The TGN volume and mean value of the DTI metrics of the post-rhizotomy lesion side were compared with those of the normal side and those of the pre-rhizotomy lesion side, and they were correlated to the post-rhizotomy visual analogue scale (VAS) pain scores after a one-year follow-up.

Results: The alterations before and after rhizotomy showed a significantly increased TGN volume and FA, and a decreased ADC, AD, and RD. The post-rhizotomy lesion side showed a significantly decreased TGN volume, FA, and $A D$ compared with the normal side; however, no significant difference in the ADC and RD were found between the groups. The TGN volume was significantly higher in the non-responders than in the responders $(P=0.016)$.

Conclusion: Our results may reflect that the effects of radiofrequency rhizotomy in TN patients include axonal damage with perineural edema and that prolonged swelling associated with recurrence might be predicted by MRI images. Further studies are necessary to understand how DTI metrics can quantitatively represent the pathophysiology of TN and to examine the application of DTI in the treatment of TN.
\end{abstract}

Keywords: Trigeminal neuralgia, Radiofrequency rhizotomy, Diffusion tensor imaging, Nerve volume, Treatment outcome

\footnotetext{
* Correspondence: russell.tsai@gmail.com

${ }^{1}$ Department of Diagnostic Radiology, Chang Gung Memorial Hospital Chiayi

Branch, No.6 Chia-Pu Rd. West Sec., Chiayi County, Taiwan

Full list of author information is available at the end of the article
}

(c) The Author(s). 2019 Open Access This article is distributed under the terms of the Creative Commons Attribution 4.0 International License (http://creativecommons.org/licenses/by/4.0/) which permits unrestricted use, distribution, and reproduction in any medium, provided you give appropriate credit to the original author(s) and the source, provide a link to the Creative Commons license, and indicate if changes were made. The Creative Commons Public Domain Dedication waiver (http://creativecommons.org/publicdomain/zero/1.0/) applies to the data made available in this article, unless otherwise stated. 


\section{Background}

Trigeminal neuralgia ( $\mathrm{TN}$ ) is a common cause of facial pain and is characterized by a recurrent sudden onset of electric shock-like pain that is localized to the sensory supply area of the trigeminal nerve (TGN). TN is typically induced by a normally non-painful mechanical irritation, and TN patients are usually pain-free between pain attacks [1]. The most common cause of TN is neurovascular compression of the TGN at the root entry zone [2], although the exact pathogenesis is still debated. Previous studies on the pathology of TN demonstrated demyelination of the TGN in patients with TN by ultrastructural and histological analyses [2-4]. The alteration of diffusion tensor imaging (DTI) metrics, including decreased fractional anisotropy (FA), increased radial diffusivity (RD), and no change in axial diffusivity (AD), could identify the same microstructural abnormality by non-invasive means [5-12].

Trigeminal neuralgia is treated by anticonvulsants, microvascular decompression, or minimally invasive percutaneous lesioning of the TGN, such as radiofrequency rhizotomy [13]. Radiofrequency rhizotomy was first used to treat chronic pain in 1974 [14], and Lopez BC et al. showed that percutaneous radiofrequency rhizotomy provides a high satisfaction with complete pain relief and low side effects. Among the various interventional pain therapies, radiofrequency rhizotomy provides the highest initial pain free experience; however, $15-20 \%$ of patients experience recurrent TN within 12 months [15].

Several studies have found abnormal DTI metrics and volume changes at trigeminal nerve in patients with TN $[6,9,16-19]$. Liu et al. reported that the FA reduction is correlated with visual analogue scale (VAS) [9], and DeSouza et al. demonstrated DTI metrics correlated with pain scores following treatment [16], which suggests that DTI metrics could be an imaging biomarker for monitoring clinical severity and treatment outcomes. By MRI volumetry, the preoperative volume of affected trigeminal nerve was significant reduced at cistern segment compared to the unaffected side in patients with TN $[6,17,18]$. Leal et al. [20] further suggested that the volume variance is significantly correlated with the severity of the compression; there is a smaller TGN volume in Grade 3 (indentation) than in Grade 1 (contact). However, it is not clear whether volume variance or DTI metrics can help predict long-term outcomes after intervention. The aim of this study was to investigate the microstructural tissue changes before and after radiofrequency rhizotomy of the TGN in patients with TN by multiple DTI metrics (FA, AD, and RD) and the nerve volumetric change and to determine whether recurrence can be predicted with DTI metrics obtained at the initial post-rhizotomy evaluation.

\section{Methods}

\section{Participants}

Thirty-seven patients with TN were prospectively enrolled in this study. All of the patients were diagnosed as having $\mathrm{TN}$ according to the criteria of the International Headache Society for TN [21]. All of the patients underwent first-time MRI and received radiofrequency rhizotomy less than 1 month between the first-time MRI and the clinical evaluation. Post-interventional MRI was performed 2 weeks after the radiofrequency rhizotomy. Additionally, the VAS pain scores were assessed twice, once before the rhizotomy (pre-rhizotomy VAS) and 1 year after the rhizotomy (post-rhizotomy VAS). Specifically, post-rhizotomy VAS scores of 0,1 , and 2 are interpreted as responders, and a post-rhizotomy VAS score of more than 2 and receiving secondary rhizotomy within 1 year are interpreted as non-responders (Fig. 1). Written informed consent was obtained from each participant, and the institutional review board of Chang Gung Memorial Hospital at Chiayi approved this study.

\section{MRI acquisition and processing}

All of the data were collected with a 3 Tesla Siemens Verio MRI system (Siemens Medical System, Erlangen, Germany) using a 32-channel head coil. The DTI sequences were obtained using a readout-segmented echoplanar imaging (RS-EPI) sequence (Syngo RESOLVE; Siemens Medical System) with the following parameters: matrix size $=110 \times 110 ; \mathrm{FOV}=220 \mathrm{~mm}$; section thickness $=2 \mathrm{~mm}$; readout segments $=5$; slice $=20$ without a gap; $\mathrm{b}$ value $=0$ and $1000 \mathrm{~s} / \mathrm{mm}^{2}$; diffusion directions $=$ 30; $\mathrm{TR}=2800 \mathrm{~ms} ; \mathrm{TE} 1 / \mathrm{TE} 2=70 \mathrm{~ms} / 95 \mathrm{~ms}$; spatial resolution $=2 \mathrm{~mm} \times 2 \mathrm{~mm} \times 2 \mathrm{~mm}$; echo spacing $=0.32 \mathrm{~ms}$; echo reading time $=7.04 \mathrm{~ms}$; and acquisition time: $8 \mathrm{~min}$ and $51 \mathrm{~s}$. 3D MP-RAGE anatomical images were obtained using a gradient echo sequence with the following parameters: $\mathrm{TR}=1900 \mathrm{~ms}$; $\mathrm{TE}=2.98 \mathrm{~ms} ; \mathrm{FOV}=230 \mathrm{~mm}$; matrix $=220 \times 256$; slice number: 160 ; spatial resolution of $0.9 \mathrm{~mm} \times 0.9 \mathrm{~mm} \times 0.9 \mathrm{~mm}$; and acquisition time: 5 min and $59 \mathrm{~s}$. DSI Studio software package utilities (http://dsi-studio.labsolver.org/) were used for the post-processing of the DTI data. The methods used for processing the DTI data have been previously reported [10]. Briefly, the DTI maps were co-registered to the 3D MP-RAGE anatomical images in the axial plane. Then, the regions of interest (ROIs) were placed onto the co-registered image and at the slice, which has the largest number of voxels at the cistern segment of the TGN. All of the imaging voxels covering the cisternal segment of the TGN were manually selected on the DTI images by two independent neuroradiologists (YH Tsai and $\mathrm{HH}$ Weng) who were blinded to the patient data, including the side of pain and surgical outcome. The trigeminal cistern segment ROI was 7 voxels in size. The 


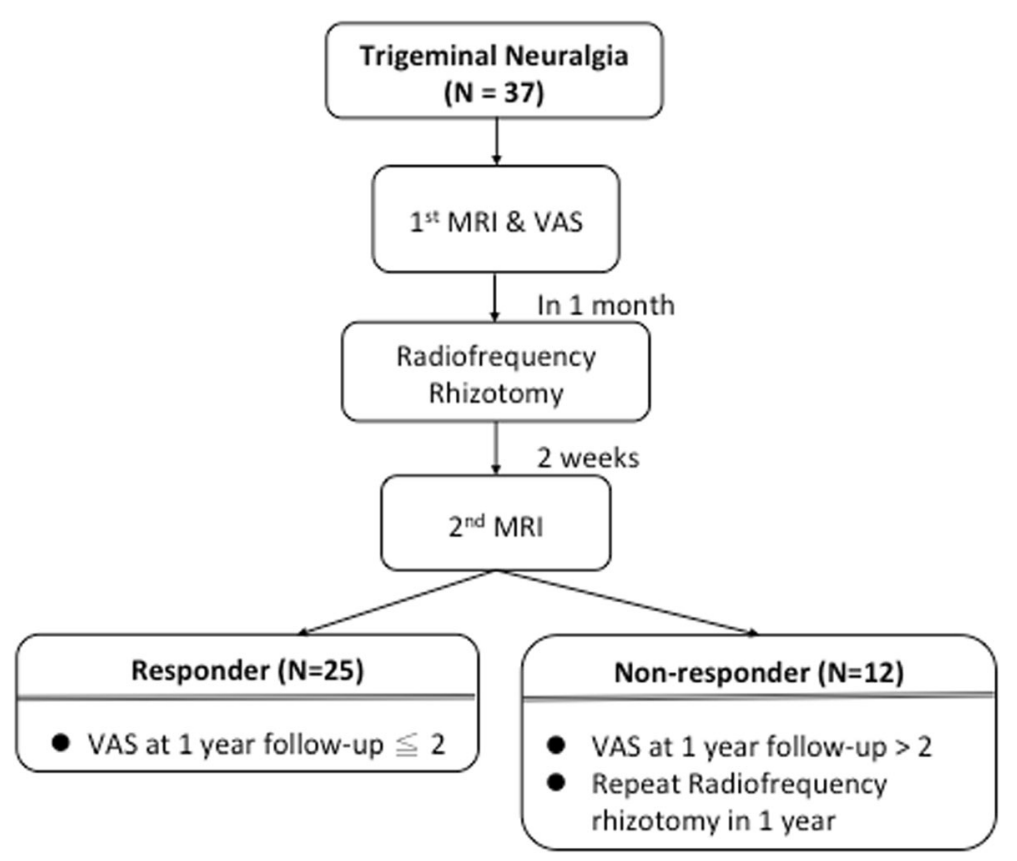

Fig. 1 A flowchart of the patient selection and study workflow

average DTI metrics of all of the voxels within the ROI, including the $\mathrm{ADC}, \mathrm{FA}, \mathrm{AD}$, and $\mathrm{RD}$, were then separately calculated by the two observers. The volume of the cisternal segment of the TGN was manually measured on the 3D MP-RAGE anatomical images using ImageJ software (https://imagej.nih.gov/ij/).

\section{Radiofrequency rhizotomy}

Percutaneous radiofrequency rhizotomy was performed by an experienced neurosurgeon (JT Yang). The rhizotomy needle was inserted under CT guidance, and the precise location was confirmed by three-dimensional image reconstruction using $1.25 \mathrm{~mm}$-thick slices (Advantage Workstation 4.0, GE Medical Systems, WI, U.S.A.). The subsequent location and lesioning were determined by the reproduction of paresthesia upon stimulation covering the distribution of a specific division of the TGN. The lesion at the Gasserian ganglion was made by radiofrequency thermocoagulation (Radionics, Inc. Burlington, MA, USA) at $65^{\circ} \mathrm{C}$ for $100 \mathrm{~s}$ and then at $70^{\circ} \mathrm{C}$ for another $100 \mathrm{~s}[22,23]$.

\section{Statistical analysis}

All of the DTI metrics, including the ADC, FA, AD, and $\mathrm{RD}$, were tested for normality of distribution using the Kolmogorov-Smirnov test. The volumes and values of the DTI metrics of the post-rhizotomy lesion side of the TGN were compared to those of the normal side and to those of the pre-rhizotomy lesion side by using a paired sample $\mathrm{t}$-test. In the analysis of the prognosis of the patient, an independent sample t-test was used to compare the mean
$\mathrm{FA}, \mathrm{ADC}, \mathrm{AD}$, and $\mathrm{RD}$ between the responders and non-responders. A comparison between the baseline characteristics of the responders and the non-responders was assessed by using the Mann-Whitney $U$ test and Fisher exact test. Multiple comparisons were statistically corrected with Bonferroni procedure $(p<0.05 / 7)$. For statistical analysis, we used the calculated mean values from the two observers. Inter-observer agreement was examined using the intraclass correlation coefficient (ICC). All of the statistical calculations were performed with SPSS V.18 software (SPSS, Chicago, IL).

\section{Results}

Baseline characteristics

The baseline characteristics of the participants are summarized in Table 1. A total of 37 patients were included, 13 males and 24 females, aged $43-87$ years (mean 59.8

Table 1 Summary of the patient characteristics

\begin{tabular}{ll}
\hline Characteristic & Mean (SD) or n (percentage) \\
\hline Total number of patients & 37 \\
Age, yr. & $59.8(7.6)$ \\
Male gender & $13(35.1 \%)$ \\
Left side & $11(29.7 \%)$ \\
Duration, mo. & $92.7(89.4)$ \\
VAS & \\
$\quad$ Pre-Radiofrequency rhizotomy & $9.2(0.9)$ \\
$\quad$ Post-Radiofrequency rhizotomy & $2.2(3.2)$ \\
\hline
\end{tabular}


years). The left side was affected in 11 of the patients, while the right side was affected in 26 of the patients. The mean disease duration was $92.7 \pm 89.4$ months.

\section{DTI metrics of lesion side TGN: a comparison between pre-rhizotomy and post-rhizotomy}

The ICC showed a good inter-observer reliability for the measurement of the pre-rhizotomy FA of the affected TGN (average measure of the $\mathrm{ICC}=0.898$ ). The differences in the pre-rhizotomy and post-rhizotomy DTI metrics of the lesion side are shown in Table 2 and Fig. 2. The post-rhizotomy volume of the TGN $\left(56.4 \pm 25.0 \mathrm{~mm}^{3}\right)$ was significantly increased compared to the pre-rhizotomy volume of the TGN $(48.6 \pm 18.7)(P=0.014)$. The post-rhizotomy FA $(0.306 \pm$ $0.051)$ was greater than the pre-rhizotomy FA $(0.268 \pm 0.093)$ $(P=0.015)$ but not significant after multiple comparison correction. The ADC, $\mathrm{AD}$, and $\mathrm{RD}$ were lower at post-rhizotomy $\left(1.484 \pm 0.190 \times 10^{-3} \mathrm{~mm}^{2} / \mathrm{s}, 1.953 \pm 0.244 \times\right.$ $10^{-3} \mathrm{~mm}^{2} / \mathrm{s}$, and $1.249 \pm 0.177 \times 10^{-3} \mathrm{~mm}^{2} / \mathrm{s}$, respectively) than at pre-rhizotomy $\left(1.640 \pm 0.261 \times 10^{-3} \mathrm{~mm}^{2} / \mathrm{s}, 2.075 \pm\right.$ $0.242 \times 10^{-3} \mathrm{~mm}^{2} / \mathrm{s}$, and $1.423 \pm 0.299 \times 10^{-3} \mathrm{~mm}^{2} / \mathrm{s}$, respectively) ( $P=0.001,0.016$, and 0.001 , respectively). The difference of $\mathrm{AD}$ did not reach statistically significant after multiple comparison correction.

\section{Post-rhizotomy DTI metrics of the TGN: a comparison between the lesion side and contralateral side}

The differences in the DTI metrics between the lesion side and contralateral side after the rhizotomy are shown in Table 3. The volume of the TGN of the lesion side $(56.4 \pm 25.0)$ was significantly smaller than that of the unaffected side $(66.6 \pm 21.8)(P=.005)$ (Fig. 3a). The FA and $\mathrm{AD}$ of the affected side were significantly lower than those of the unaffected side $(P=0.012$ and 0.001 , respectively). However, after multiple comparison correction, FA was not statistically significant. There were no statistically significant differences between the affected and unaffected sides of the patients for the ADC and the RD ( $P=0.075$ and 0.640 , respectively) (Fig. 2$)$.

\section{Therapeutic outcomes}

The baseline characteristics of the responders and non-responders are shown in Table 4. There were no significant differences in the age, sex, lesion side, disease duration, and pre-rhizotomy VAS score between the responders and non-responders $(P=0.618, P=0.874, P=$ $0.228, P=0.616$, and $P=0.059$, respectively). The TGN volume of the pre-rhizotomy lesion side and DTI metrics also showed no significant differences between groups. After the rhizotomy, the volume of the TGN of the lesion side was significantly higher in the non-responders $\left(70.4 \pm 24.9 \mathrm{~mm}^{3}\right)$ than in the responders $(49.7 \pm 22.6)(P=0.016)$ (Fig. 3b), yet no significant differences in the post-RFA FA, ADC, AD and RD (Table 4).

\section{Discussion}

This paper is an extension of our previous study [10] -- further explorations of longitudinal microstructural changes of trigeminal nerve after radiofrequency rhizotomy using MRI. Besides, we try to identify prognostic imaging biomarker by MRI that performed 2 weeks after rhizotomy. As mentioned in the previous study, forty-seven patients with $\mathrm{TN}$ were prospectively enrolled into this study in the beginning, while four patients who had history of $\mathrm{TN}$ on the contralateral side were excluded. Among the 43 patients with unilateral TN, 37 received radiofrequency rhizotomy after MRI. The result of the previous study showed that there was no correlation between pre-rhizotomy DTI metrics, volume and the effective VAS score reduction at one-month follow up [10].

In this study, we demonstrated that patients with trigeminal neuralgia who received radiofrequency rhizotomy may have had axonal injury with perineural edema at the cisternal segment of the TGN after the intervention. These microstructural abnormalities are characterized by a higher $\mathrm{FA}$ and lower $\mathrm{ADC}, \mathrm{AD}$, and $\mathrm{RD}$ in the post-rhizotomy lesion side compared with the pre-rhizotomy lesion side and also by a decreased FA and AD compared with the normal side. The TGN volume of the lesion side increased after radiofrequency rhizotomy, but the volume is still smaller than that of the unaffected side (Fig. 4). We also observed a significantly higher TGN volume of the post-rhizotomy lesion side in the non-responders compared to that of the responders, and there was no significant difference in the volume before the radiofrequency rhizotomy between the groups $(P=0.496)$.

Table 2 Summary of the differences between the pre-radio frequency rhizotomy and post-radiofrequency rhizotomy DTI metrics of the lesion side $(N=37)$

\begin{tabular}{|c|c|c|c|}
\hline & Pre-rhizotomy (SD) & Post-rhizotomy (SD) & $P$ value \\
\hline Volume $\left(\mathrm{mm}^{3}\right)$ & $48.6(18.7)$ & $56.4(25.0)$ & $0.014^{*}$ \\
\hline Fractional anisotropy & $0.268(0.093)$ & $0.306(0.051)$ & $0.015^{*}$ \\
\hline Apparent diffusion coefficient $\left({ }^{*} 10^{-3}\right)$ & $1.640(0.261)$ & $1.484(0.190)$ & $0.001^{*}$ \\
\hline Axial diffusivity $\left({ }^{*} 10^{-3}\right)$ & $2.075(0.242)$ & $1.953(0.244)$ & $0.016^{*}$ \\
\hline Radial diffusivity $\left({ }^{*} 10^{-3}\right)$ & $1.423(0.299)$ & $1.249(0.177)$ & $0.001^{*}$ \\
\hline
\end{tabular}

${ }^{*} P<0.05$ was considered to indicate a significant difference 


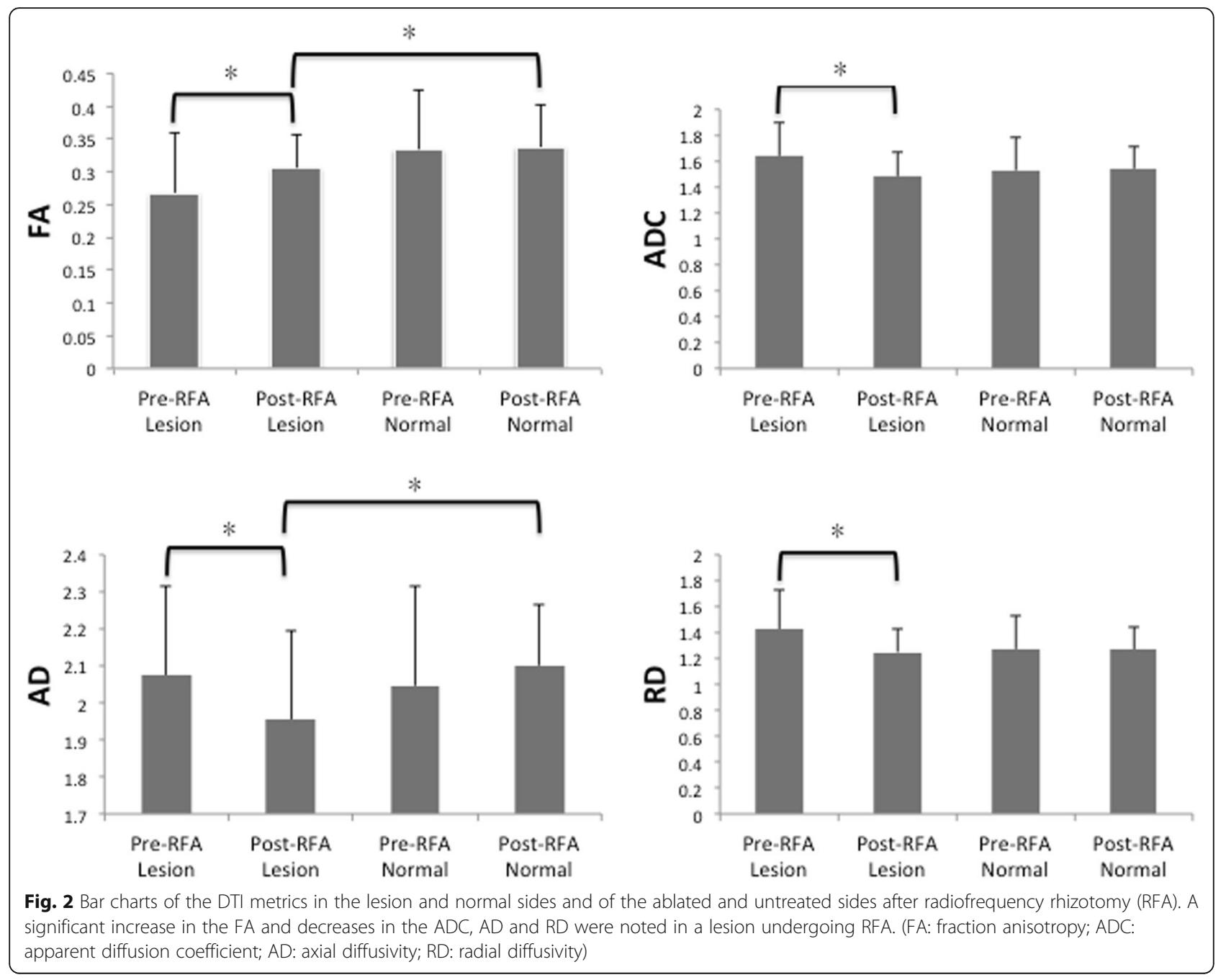

Diffusion tensor imaging is based on the diffusion of free water protons along multiple directions in space, which enable the assessment of tissue architecture and microdynamics in vivo [24]. FA and ADC are parameters that are commonly used that represent a simplified description of water diffusion. Directional diffusivity metrics including axial and radial diffusivity ( $A D$ and $R D$ ) give additional evaluations of diffusivity parallel and perpendicular to fiber orientation, respectively, and are hypothesized to have a more specific differentiation of axonal integrity, demyelination, or edema $[25,26]$ as diffusion is particularly sensitive to changes in the architecture of cellular membrane under certain pathological conditions [12].

The histopathological changes of trigeminal nerve after radiofrequency lesioning are still debated. Previous studies assumed that radiofrequency rhizotomy treatment of TN is based on the fact that the $\mathrm{A} \delta$ and $\mathrm{C}$ fibers

Table 3 Summary of the differences in the DTI metrics between the lesion side and contralateral side of the trigeminal nerve after radiofrequency rhizotomy $(\mathrm{N}=37)$

\begin{tabular}{llll}
\hline & Lesion Mean (SD) & Normal Mean (SD) & P value \\
\hline Volume $\left(\mathrm{mm}^{3}\right)$ & $56.4(25.0)$ & $66.6(21.8)$ & $0.005^{*}$ \\
Fractional anisotropy & $0.306(0.051)$ & $0.338(0.063)$ & $0.012^{*}$ \\
Apparent diffusion coefficient $\left({ }^{*} 10^{-3}\right)$ & $1.484(0.190)$ & $1.544(0.164)$ & 0.075 \\
Axial diffusivity $\left({ }^{*} 10^{-3}\right)$ & $1.953(0.244)$ & $2.101(0.163)$ & $0.001^{*}$ \\
Radial diffusivity $\left({ }^{*} 10^{-3}\right)$ & $1.249(0.177)$ & $1.265(0.177)$ & 0.640 \\
\hline
\end{tabular}

$P<0.05$ was considered to indicate a significant difference 


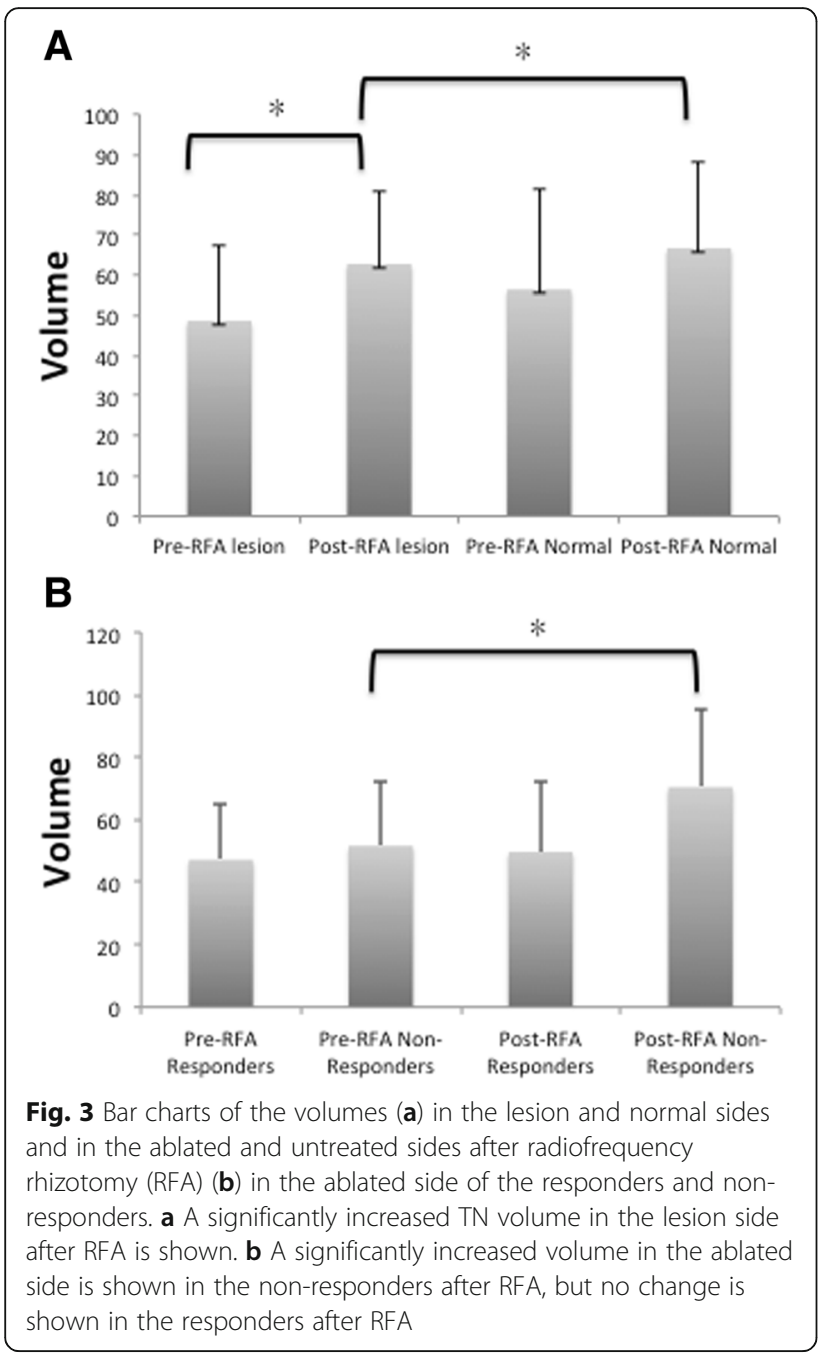

are more sensitive to thermocoagulation than the $\mathrm{A} \alpha$ and $\beta$ fibers $[27,28]$. Therefore, the irreversible damage to small, unmyelinated pain fibers blocks pain sensation without sensory and motor nerve damage when the temperature is from $55^{\circ} \mathrm{C}$ to $70^{\circ} \mathrm{C}$ [29]. However, recent research has shown that TN results from microstructural changes of trigeminal afferent neurons in the trigeminal root or ganglion and that the injury renders hyperexcitable axons [30], and pulsed radiofrequency damaged the trigger point which was mediated by peripheral low threshold myelinated $A \beta$ fibers [31]. On the contrary, Choi et al. found the neurodestructive effect was severely and non-selectively degenerated and stunted myelinated axons, swelling and absence of mitochondria, complete destruction of collagen and elastin structure [32]. Our results of an increased volume and greater FA coupled with a lower $\mathrm{ADC}, \mathrm{AD}$, and $\mathrm{RD}$ are indicative of intracellular edema [33], neuroinflammation, and axonal alterations [34] at the cisternal segment in the TGN after radiofrequency rhizotomy. In addition, compared with the normal side, the affected side showing decreased FA and AD but no significant difference in the RD, which may indicate that there is axonal damage after radiofrequency rhizotomy. Axonal injury caused by rhizotomy may damage cell membrane structure and mitochondria causing increase in cell infiltration, which could potentially reduce extracellular fluid and overall diffusion [35]. Extracellular water diffuses into the cell interior, resulting in cell swelling and an increase in the TGN volume after rhizotomy, which is consistent with our findings. Our DTI and volume findings may support the non-selective effect of radiofrequency rhizotomy under aforementioned cellular mechanism. The post-rhizotomy pathologic findings include massive edema at 2 days after rhizotomy that progressed to Wallerian degeneration at 7-10 \pm 14 days [36], which may give an explanation for ablation at the Gasserian ganglion causing tissue abnormalities at the root entry zone and pre-ganglion segment. Our results showed an increased TN volume at the time of 2 weeks post-rhizotomy, which probably indicated that the nerve is still edematous and that 2 weeks is too short of a time to cause volume loss.

Structural changes in the trigeminal nerve leading to volume loss have been well-documented. Leal et al. and Duan et al. attributed this volumetric change to atrophy and documented that the more severe atrophy of the TGN has a better clinical improvement following the surgical decompression of the nerve [20, 37]. However, it is not clear whether the volumetric change is entirely due to vessel compression or irreversible structural change. Furthermore, the correlation between the volume and outcome in treatments other than decompression surgery is not clear. We examined the effectiveness of radiofrequency rhizotomy at the time of one-year follow-up and how it impacts the cistern segment of the TGN by measuring the TGN volume and DTI metrics. Our results indicated that recurrence was associated with a significantly higher TGN volume without accompanying changes in the DTI metrics. Interestingly, there was no significant difference in the pretreatment baseline characteristics of the responders and non-responders, and there was no significant difference in TGN volume of the responders before and after rhizotomy $(P=0.496)$. The non-responders had a significantly increased TGN volume 2 weeks after the radiofrequency rhizotomy compared to before the rhizotomy $(P=0.016)$. These findings may indicate that prolonged cell swelling/inflammatory changes may be associated with recurrence. Additionally, an inadequate needle position during RFA may be the reason for recurrence, which causes a thermal effect mainly at the perineural tissue instead of at the nerve itself, thus having less of an effect of axonal damage to the TGN. Further study is indicated to support the current observation that the 
Table 4 Summary of the characteristics of the responders and the non-responders

\begin{tabular}{|c|c|c|c|}
\hline & $\begin{array}{l}\text { Responders } \\
(n=25)\end{array}$ & Non-responders $(n=12)$ & $P$ value \\
\hline Age, yr. & $59.4(8.2)$ & $60.8(6.1)$ & 0.618 \\
\hline Male & $9(36.0 \%)$ & $4(33.3 \%)$ & 0.874 \\
\hline Left side & $9(36.0 \%)$ & $2(16.7 \%)$ & 0.228 \\
\hline Duration, mo. & $97.9(91.5)$ & $81.8(87.7)$ & 0.616 \\
\hline Pre-rhizotomy VAS & $9.5(0.7)$ & $8.7(1.2)$ & 0.059 \\
\hline \multicolumn{4}{|l|}{ Pre-rhizotomy lesion side } \\
\hline Volume $\left(\mathrm{mm}^{3}\right)$ & $47.2(18.0)$ & $51.7(20.6)$ & 0.496 \\
\hline Fractional anisotropy & $0.277(0.104)$ & $0.249(0.064)$ & 0.402 \\
\hline Apparent diffusion coefficient $\left({ }^{*} 10^{-3}\right)$ & $1.617(0.261)$ & $1.690(0.268)$ & 0.434 \\
\hline Axial diffusivity $\left({ }^{*} 10^{-3}\right)$ & $2.058(0.241)$ & $2.110(0.251)$ & 0.548 \\
\hline Radial diffusivity $\left({ }^{*} 10^{-3}\right)$ & $1.396(0.306)$ & $1.480(0.288)$ & 0.434 \\
\hline \multicolumn{4}{|l|}{ Post-rhizotomy lesion side } \\
\hline Volume $\left(\mathrm{mm}^{3}\right)$ & $49.7(22.6)$ & $70.4(24.9)$ & $0.016^{*}$ \\
\hline Fractional anisotropy & $0.302(0.043)$ & $0.315(0.066)$ & 0.475 \\
\hline Apparent diffusion coefficient $\left({ }^{*} 10^{-3}\right)$ & $1.470(0.169)$ & $1.513(0.235)$ & 0.527 \\
\hline Axial diffusivity $\left({ }^{*} 10^{-3}\right)$ & $1.930(0.216)$ & $2.000(0.300)$ & 0.424 \\
\hline Radial diffusivity $\left({ }^{*} 10^{-3}\right)$ & $1.240(0.155)$ & $1.269(0.221)$ & 0.641 \\
\hline
\end{tabular}

Note - The values are the mean (standard deviation) or number (percentage)

${ }^{*} \mathrm{P}<0.05$ was considered to indicate a significant difference
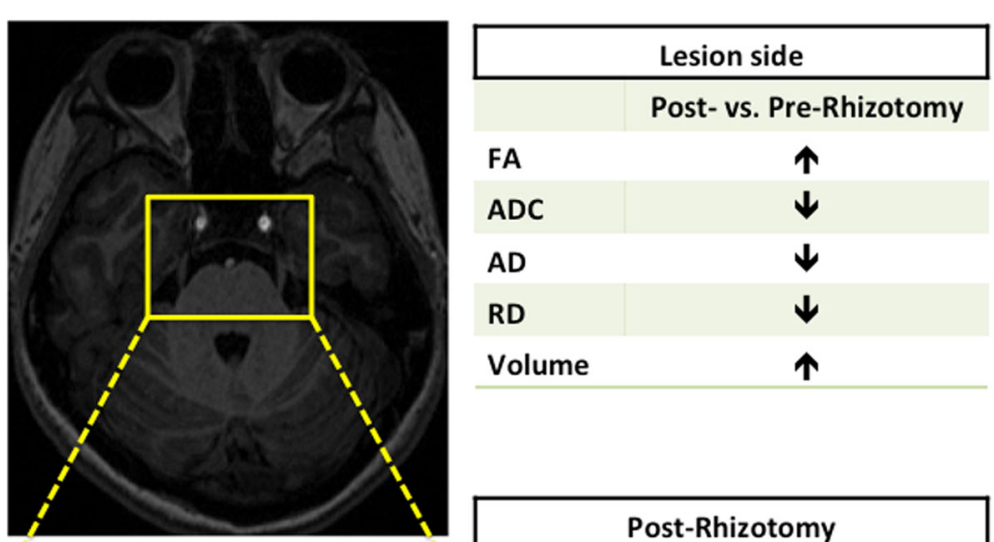

Post- vs. Pre-Rhizotomy

FA

ADC

$A D$

RD

Volume
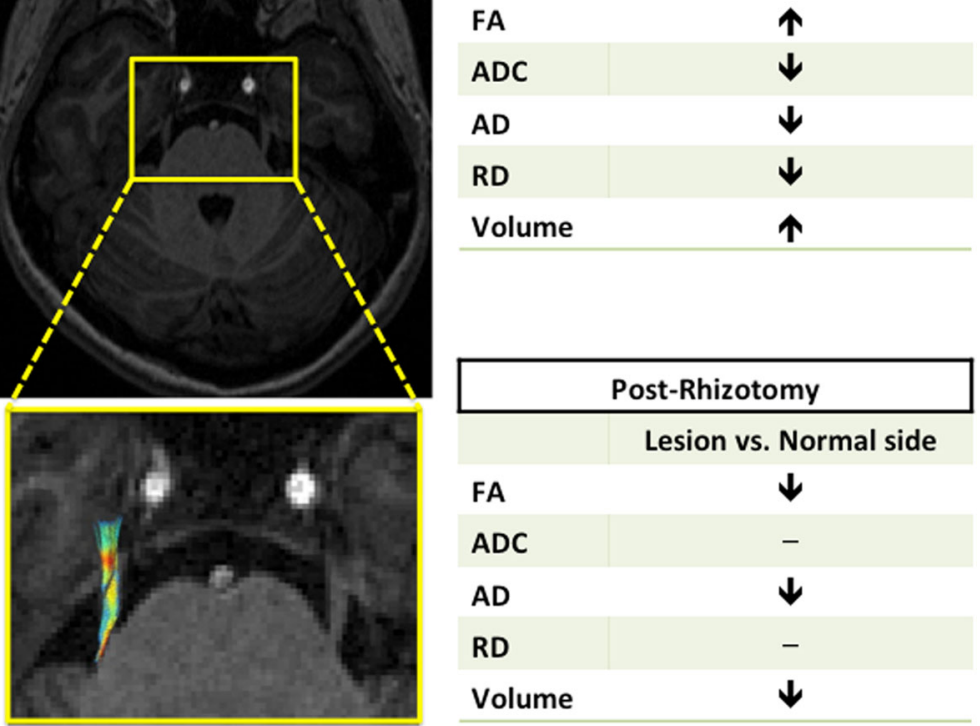

Fig. 4 A summary of changes of the volume and diffusion tensor metrics of the trigeminal nerve in a patient with trigeminal neuralgia is shown. Upper table: a comparison between the TN of the lesion side before and after RFA. Lower table: a comparison between the TN of the lesion and normal sides after RFA. (FA: fractional anisotropy; ADC: apparent diffusion coefficient; AD: axial diffusivity; RD: radial diffusivity; RFA: radiofrequency rhizotomy) 
volume changes after RFA can be an imaging biomarker to predict recurrence.

There are several limitations to our study. First, the partial volume effect, especially from imaging voxels with a cerebrospinal fluid (CSF) signal, might lead to errors in the DTI measurement. In this study, we co-registered the DTI images to MPRAGE and selected the imaging voxels in the axial slice containing the most voxels of the TGN. Each voxel can be checked simultaneously in both the DTI and MPRAGE images to make sure that the voxel is within the TGN, and the procedure was double-checked by two observers, which produced a good ICC (0.898). Other limitations include that the study population was small and that the disease duration differed between the patients, which may cause different degrees of microstructural changes and treatment benefits. However, we found no correlation between the disease duration and DTI values.

\section{Conclusions}

Our results may reflect that the effects of radiofrequency rhizotomy in TN patients include axonal damage with perineural edema and that prolonged swelling associated with recurrence might be predicted by MRI images. Further studies are necessary to understand how DTI metrics can quantitatively represent the pathophysiology of $\mathrm{TN}$ and to examine the application of DTI in the treatment of TN.

\section{Abbreviations}

AD: Axial Diffusivity; ADC: Apparent Diffusion Coefficient; DTI: Diffusion Tensor Imaging; FA: Fractional Anisotropy; RD: Radial Diffusivity; TGN: Trigeminal Nerve; TN: Trigeminal Neuralgia

\section{Acknowledgements}

Not applicable.

\section{Funding}

This study was supported by grants CMRPG6C0282 and CORPG6D0122 from Chang Gung Memorial Hospital. The funding body did not play any role in design, in the collection, analysis, and interpretation of data; in the writing of the manuscript; and in the decision to submit the manuscript for publication.

\section{Availability of data and materials}

The datasets used and/or analyzed during the current study are available from the corresponding author on reasonable request.

\section{Authors' contributions \\ YHT contributed to study conception and design, general supervision of the research group, and also critical revised the manuscript. STC involved in data interpretation and was a major contributor in writing the manuscript. JTY contribute to study conception and design, performed the radiofrequent rhizotomy, and drafted the method part of the manuscript. HHW contributed to statistical analysis and overall English language reviewing of the manuscript. HLW and MYY engaged in data acquisition and analysis, as well as imaging and figures processing. All authors read and approved the final manuscript.}

\section{Ethics approval and consent to participate}

The study obtained ethical approval (101-5250B) by the Institutional Review Board of Chang Gung Memorial Hospital, and all patients gave written informed consent.
Consent for publication

Not applicable.

\section{Competing interests}

The authors declare that they have no competing interests.

\section{Publisher's Note}

Springer Nature remains neutral with regard to jurisdictional claims in published maps and institutional affiliations.

\section{Author details}

${ }^{1}$ Department of Diagnostic Radiology, Chang Gung Memorial Hospital Chiayi Branch, No.6 Chia-Pu Rd. West Sec., Chiayi County, Taiwan. ${ }^{2}$ Department of Neurosurgery, Chang Gung Memorial Hospital Chiayi Branch, Chiayi, Taiwan. ${ }^{3}$ Department of Biomedical Engineering and Environmental Sciences, National Tsing Hua University, Hsinchu, Taiwan.

Received: 15 July 2018 Accepted: 2 April 2019

Published online: 12 April 2019

\section{References}

1. Rappaport ZH, Devor M. Trigeminal neuralgia: the role of self-sustaining discharge in the trigeminal ganglion. Pain. 1994;56(2):127-38.

2. Devor M, Govrin-Lippmann R, Rappaport ZH. Mechanism of trigeminal neuralgia: an ultrastructural analysis of trigeminal root specimens obtained during microvascular decompression surgery. J Neurosurg. 2002:96(3):532-43.

3. Love $\mathrm{S}$, Gradidge T, Coakham HB. Trigeminal neuralgia due to multiple sclerosis: ultrastructural findings in trigeminal rhizotomy specimens. Neuropathol Appl Neurobiol. 2001;27(3):238-44.

4. Hilton DA, Love S, Gradidge T, Coakham HB. Pathological findings associated with trigeminal neuralgia caused by vascular compression. Neurosurgery. 1994;35(2):299-303 discussion 303.

5. Herweh C, Kress B, Rasche D, Tronnier V, Troger J, Sartor K, Stippich C. Loss of anisotropy in trigeminal neuralgia revealed by diffusion tensor imaging. Neurology. 2007:68(10):776-8.

6. Fujiwara S, Sasaki M, Wada T, Kudo K, Hirooka R, Ishigaki D, Nishikawa Y, Ono A, Yamaguchi M, Ogasawara K. High-resolution diffusion tensor imaging for the detection of diffusion abnormalities in the trigeminal nerves of patients with trigeminal neuralgia caused by neurovascular compression. J Neuroimaging. 2011;21(2):e102-8.

7. Lutz J, Linn J, Mehrkens JH, Thon N, Stahl R, Seelos K, Bruckmann H, Holtmannspotter M. Trigeminal neuralgia due to neurovascular compression: high-spatial-resolution diffusion-tensor imaging reveals microstructural neural changes. Radiology. 2011;258(2):524-30.

8. Leal PR, Roch JA, Hermier M, Souza MA, Cristino-Filho G, Sindou M. Structural abnormalities of the trigeminal root revealed by diffusion tensor imaging in patients with trigeminal neuralgia caused by neurovascular compression: a prospective, double-blind, controlled study. Pain. 2011; 152(10):2357-64

9. Liu Y, Li J, Butzkueven H, Duan Y, Zhang M, Shu N, Li Y, Zhang Y, Li K. Microstructural abnormalities in the trigeminal nerves of patients with trigeminal neuralgia revealed by multiple diffusion metrics. Eur J Radiol. 2013:82(5):783-6.

10. Chen ST, Yang JT, Yeh MY, Weng HH, Chen CF, Tsai YH. Using diffusion tensor imaging to evaluate microstructural changes and outcomes after radiofrequency Rhizotomy of trigeminal nerves in patients with trigeminal neuralgia. PLoS One. 2016;11(12):e0167584.

11. DeSouza DD, Hodaie M, Davis KD. Abnormal trigeminal nerve microstructure and brain white matter in idiopathic trigeminal neuralgia. Pain. 2014;155(1):37-44.

12. DeSouza DD, Hodaie M, Davis KD. Structural magnetic resonance imaging can identify trigeminal system abnormalities in classical trigeminal neuralgia. Front Neuroanat. 2016;10:95.

13. Obermann M. Treatment options in trigeminal neuralgia. Ther Adv Neurol Disord. 2010;3(2):107-15

14. Uematsu S, Udvarhelyi GB, Benson DW, Siebens AA. Percutaneous radiofrequency rhizotomy. Surg Neurol. 1974;2(5):319-25.

15. Kanpolat Y, Savas A, Bekar A, Berk C. Percutaneous controlled radiofrequency trigeminal rhizotomy for the treatment of idiopathic trigeminal neuralgia: 25-year experience with 1,600 patients. Neurosurgery. 2001;48(3):524-32; discussion 532-524. 
16. DeSouza DD, Davis KD, Hodaie M. Reversal of insular and microstructural nerve abnormalities following effective surgical treatment for trigeminal neuralgia. Pain. 2015;156(6):1112-23.

17. Erbay SH, Bhadelia RA, O'Callaghan M, Gupta P, Riesenburger R, Krackov W, Polak JF. Nerve atrophy in severe trigeminal neuralgia: noninvasive confirmation at MR imaging--initial experience. Radiology. 2006;238(2):689-92.

18. Horinek D, Brezova V, Nimsky C, Belsan T, Martinkovic L, Masopust V, Vrana J, Kozler P, Plas J, Krysl D, et al. The MRI volumetry of the posterior fossa and its substructures in trigeminal neuralgia: a validated study. Acta Neurochir. 2009;151(6):669-75.

19. XXIst Symposium Neuroradiologicum. Neuroradiology 2018, 60(Suppl 1):1-406

20. Leal PR, Barbier C, Hermier M, Souza MA, Cristino-Filho G, Sindou M. Atrophic changes in the trigeminal nerves of patients with trigeminal neuralgia due to neurovascular compression and their association with the severity of compression and clinical outcomes. J Neurosurg. 2014;120(6): 1484-95.

21. Headache Classification Committee of the International Headache S. The international classification of headache disorders, 3rd edition (beta version). Cephalalgia. 2013;33(9):629-808.

22. Lin MH, Lee MH, Wang TC, Cheng YK, Su CH, Chang CM, Yang JT. Foramen ovale cannulation guided by intra-operative computed tomography with integrated neuronavigation for the treatment of trigeminal neuralgia. Acta Neurochir. 2011;153(8):1593-9.

23. Yang JT, Lin $\mathrm{M}$, Lee $\mathrm{MH}$, Weng HH, Liao HH. Percutaneous trigeminal nerve radiofrequency rhizotomy guided by computerized tomography with threedimensional image reconstruction. Chang Gung Med J. 2010;33(6):679-83.

24. Le Bihan D. Molecular diffusion, tissue microdynamics and microstructure. NMR Biomed. 1995;8(7-8):375-86.

25. Song SK, Sun SW, Ramsbottom MJ, Chang C, Russell J, Cross AH. Dysmyelination revealed through MRI as increased radial (but unchanged axial) diffusion of water. Neuroimage. 2002;17(3):1429-36.

26. Alexander AL, Lee JE, Lazar M, Field AS. Diffusion tensor imaging of the brain. Neurotherapeutics. 2007:4(3):316-29.

27. Kanpolat $Y$, Onol B. Experimental percutaneous approach to the trigeminal ganglion in dogs with histopathological evaluation of radiofrequency lesions. Acta Neurochir Suppl (Wien). 1980;30:363-6.

28. Smith HP, McWhorter JM, Challa VR. Radiofrequency neurolysis in a clinical model. Neuropathological correlation. J Neurosurg. 1981;55(2):246-53.

29. Frigyesi TL, Siegfried J, Broggi G. The selective vulnerability of evoked potentials in the trigeminal sensory root of graded thermocoagulation. Exp Neurol. 1975;49(1 Pt 1):11-21.

30. Devor M, Amir R, Rappaport ZH. Pathophysiology of trigeminal neuralgia: the ignition hypothesis. Clin J Pain. 2002;18(1):4-13.

31. Sandkuhler J. Models and mechanisms of hyperalgesia and allodynia. Physiol Rev. 2009;89(2):707-58.

32. Choi S, Choi HJ, Cheong Y, Chung SH, Park HK, Lim YJ. Inflammatory responses and morphological changes of radiofrequency-induced rat sciatic nerve fibres. Eur J Pain. 2014;18(2):192-203.

33. Veeramuthu V, Narayanan V, Kuo TL, Delano-Wood L, Chinna K, Bondi MW Waran V, Ganesan D, Ramli N. Diffusion tensor imaging parameters in mild traumatic brain injury and its correlation with early neuropsychological impairment: a longitudinal study. J Neurotrauma. 2015;32(19):1497-509.

34. Hung PS, Chen DQ, Davis KD, Zhong J, Hodaie M. Predicting pain relief: use of pre-surgical trigeminal nerve diffusion metrics in trigeminal neuralgia. Neuroimage Clin. 2017;15:710-8.

35. Aung WY, Mar S, Benzinger TL. Diffusion tensor MRI as a biomarker in axonal and myelin damage. Imaging Med. 2013;5(5):427-40.

36. Podhajsky RJ, Sekiguchi Y, Kikuchi S, Myers RR. The histologic effects of pulsed and continuous radiofrequency lesions at 42 degrees $C$ to rat dorsal root ganglion and sciatic nerve. Spine (Phila Pa 1976). 2005;30(9):1008-13.

37. Duan Y, Sweet J, Munyon C, Miller J. Degree of distal trigeminal nerve atrophy predicts outcome after microvascular decompression for type 1a trigeminal neuralgia. J Neurosurg. 2015;123(6):1512-8.

Ready to submit your research? Choose BMC and benefit from:

- fast, convenient online submission

- thorough peer review by experienced researchers in your field

- rapid publication on acceptance

- support for research data, including large and complex data types

- gold Open Access which fosters wider collaboration and increased citations

- maximum visibility for your research: over $100 \mathrm{M}$ website views per year

At $\mathrm{BMC}$, research is always in progress.

Learn more biomedcentral.com/submissions 